\title{
RESPONSE OF MELOIDOGYNE HAPLA TO MYCORRHIZA FUNGI INOCULATION ON PYRETHRUM
}

\author{
Waceke, J.W., ${ }^{1}$ Waudo, S.W. ${ }^{1}$ and Sikora, R. ${ }^{2}$ \\ ${ }^{1}$ Botany Department, Kenyatta University, P.O.Box 43844, Nairobi, Kenya \\ ${ }^{2}$ Institute of Plant Diseases, University of Bonn, Nussallee 9, D- 53153, Germany
}

\begin{abstract}
Five arbuscular mycorrhiza fungi $(A M F)$ isolated from pyrethrum were screened in the greenhouse for efficacy in improving pyrethrum growth and in suppressing a root-knot nematode, Meloidogyne hapla. The fungi screened were Glomus spp. (isolates LM61, ML34 and ML35), Scutellospora sp. (isolate KS74) and Gigaspora sp. (isolate LM83). A $20 \mathrm{~g}$ mixed fungal inoculum was incorporated into sterilized sand-soil mixture before transplanting 6-week-old pyrethrum seedlings. The inoculum consisted of the growth medium, spores, external mycelia and infected root segments. The plants were inoculated with $6000 \mathrm{M}$. hapla second stage juvenile (J-2) 3 months after fungal inoculation. Dry shoot weights, fresh root weights, percent root colonization by the fungi, nematode gall indices, number of eggs and females in the root system and number of J-2 in the soil were determined at the end of the experiment, two months after nematode inoculation. Glomus LM61 and Scutellospora KS74 significantly improved top biomasses of fungus-treated and fungus-nematodetreated plants. Glomus LM61was more effective (33\% top biomass increase). Glomus ML34 and ML35 and Gigaspora LM83 improved top biomasses of fungus-nematode-treated plants. Scutellospora KS74 and Glomus ML34 significantly increased fresh root weights of pyrethrum by $45 \%$ and 50\%, respectively. Glomus LM61, Scutellospora KS74 and Gigaspora LM83 caused 86\%, $32 \%$ and $37 \%$ nematode suppression, respectively. All the fungal isolates significantly reduced the number of females and J-2. The presence of nematodes in fungus-treated plants did not affect root colonization by the fungi except in plants treated with Glomus ML34 and ML35.
\end{abstract}

Key words: Meloidogyne hapla, Mycorrhiza fungi, pyrethrum

\section{INTRODUCTION}

Kenya is the leading pyrethrum (Chrysanthemum cinerariefolium Vis.) producer worldwide. Currently, Kenya supplies 67 - $80 \%$ of the world pyrethrum requirements (Pers. Comm. Pyrethrum Board of Kenya (PBK)). The dried flowers are a source of pyrethrins, which are active ingredients of natural insecticides.

Meloidogyne hapla Chitwood, a root-knot nematode, accounts for $95 \%$ of the plant-parasitic nematode populations associated with pyrethrum in Kenya (Parlevliet and Brewer, 1971). The nematode causes 20-30\% pyrethrum yield losses, a decrease in flower size and pyrethrin content, stunting, chlorosis, wilting and predisposes infected plants to infection by root-rot and wilt fungal pathogens (Warui et al., 1991).

The high cost of nematicides, and environmental and health hazards posed by their use in the management of
M. hapla, as well as the relatively low economic value of recommended rotational crops (maize) involving the long rotational periods (3-4 years)(Wanjala, 1992) the development of new $M$. hapla races pathogenic to hitherto resistant pyrethrum clones (Triantaphyllou, 1985) make imperative a search for viable alternatives in the management of the nematode.

Components of a viable control package should be cost effective and environmentally safe. Arbuscular mycorrhiza fungi (AMF), obligate endophytic symbionts have the potential of suppressing pathogens and associated diseases (Ingham, 1988; Francl, 1993; Lindermann, 1994) and could therefore provide such an alternative.

Glomus mosseae (Nicol. and Gerd.) Gerd. and Trappe, $G$. macrocarpum Tul and Tul and G. fasciculatum Walker and Koske have been reported to reduce disease severity and suppress development of Meloidogyne incognita (Kofoid and White) Chitwood and M. hapla (Sikora, 1979; Kellam 
and Schenck, 1980). Besides suppressing disease, AMF promote plant growth and yield, enhance plant water relations, improve soil aggregation and structure and ameliorate aluminium and iron toxicity (Harley and Smith, 1983; Janos, 1987). Use of AMF in the long term would thus favour an agricultural system that is both production and protection oriented thus enhancing stabilization of agroecosystems.

In spite of all these benefits associated with AMF, a literature search revealed that no work has been done to assess interaction between M. hapla and AMF that are indigenous to pyrethrum fields in Kenya. This study was, therefore, designed to screen AMF that are indigenous to pyrethrum fields for efficacy in suppressing M. hapla and in improving pyrethrum growth.

\section{MATERIALSANDMETHODS}

\section{Inoculum production and inoculation procedure}

\section{Arbuscular mycorrhiza fungi}

Greenhouse tests were conducted to investigate effects of five AMF isolates in improving pyrethrum growth and in suppressing M. hapla. The fungi screened were Glomus spp. (isolates LM61, ML34 and ML35), Scutellospora sp. (isolate KS74) and Gigaspora sp. (isolate LM83). The fungi were obtained from soils sampled from the rhizosphere of pyrethrum growing in three main pyrethrum growing zones; Kisii (KS), Limuru (LM) and Molo (ML). The areas represented low (1800-2100m), mid (2100-2600m) and high altitude (2600-3100m) zones, respectively.

Soil samples from each study site were thoroughly mixed before taking three $300 \mathrm{~g}$ sub-samples for physico-chemical characteristic analysis and five $50 \mathrm{~g}$ sub-samples for AMF spore extraction. The mineral content analysis of the soil was done at National Agricultural Research Laboratories (NARL). About $2 \mathrm{~kg}$ of soil was used to initiate soil trap cultures for maintaining the fungal populations. The remainder of the soil was used as a growth medium in the experimental trials for the respective fungal isolates.

Arbuscular mycorrhiza fungal spores were extracted from soil using a combination of wet-sieving and decanting (Gerdeman and Nicolson, 1963) and sucrose-centrifugation techniques (Jenkins, 1964). The spores were characterized following Morton (1988), Schenck and Perez (1987) and Walker (1983) and identified to generic taxon. The isolates were cultured on tropical kudzu (Pueraria phasioloides Benth), an obligate mycotrophic legume. Healthy spores of each isolate were placed on root tips of $P$. phasioloides seedlings freshly germinated in the greenhouse on autoclaved sand. Before spore placement, the seedling was placed in a 2-cm-depression made in sterilized growth medium contained in a 7-cm-diameter plastic pot. After spore placement, the depression was gently covered with the growth medium taking care not to dislodge the spore from the root tip. Plants were placed in the greenhouse and watered appropriately. Plants were supplied with Hoagland's solution minus phosphorus. General greenhouse sanitation was maintained to ensure purity of the cultures. Cultures were checked 6 weeks after spore placement and monthly thereafter for sporulation. The cultures were then maintained on pyrethrum and served as sources of AMF inocula.

Twenty grams of the mixed fungal inoculum obtained from a 3 month-old culture was placed in a 3-cm-depression made in sterilized soil contained in a $15-\mathrm{cm}$-diameter plastic pot. Soils from which AM fungal isolates were obtained served as the growth media for the respective fungal isolates. The soils from Kisii ( $\mathrm{pH} 4.7$, clay loam, $\mathrm{P}=7 \mathrm{ppm}$ ) and Molo (pH5, clay loam, $\mathrm{P}=6 \mathrm{ppm}$ ) sampling sites unlike those from Limuru (pH5.5, loam, $\mathrm{P}=26-68 \mathrm{ppm}$ ) were mixed with sand (4:1) to improve soil texture. The soil: sand mixture was sterilized by autoclaving for two separate hour periods at $121 \mathrm{C}$ at $103 \mathrm{Kpa}$. The inoculum consisted of the growth medium, spore, external mycelia and infected root segments. After inoculum placement, 6-week-old-pyrethrum seedlings were planted so that the inoculum was directly below the pyrethrum root systems. Uninoculated plants served as the controls. Pyrethrum variety P4 recommended for it's high flower yield and pyrethrin content (Ikahu and Ngugi, 1989) was used as the test plant throughout the study. The pyrethrum seeds were germinated in sterile sand: soil (1:4) mixture and transplanted after six weeks. The plants were watered as required and supplied with $0.3 \%$ Wuxal nutrient solution $\left(12 \% \mathrm{~N}, 4 \% \mathrm{P}_{2} \mathrm{O}_{5}, 6 \% \mathrm{~K}_{2} \mathrm{O}, 0.02 \%\right.$ Boron and $0.01 \%$ Copper) monthly.

\section{Meloidogyne hapla}

Meloidogyne hapla used in this study was obtained from galled pyrethrum roots sampled from pyrethrum fields where the fungi were obtained. The nematodes were maintained on tomato (Lycopersicon esculentum Mill. cv. Money maker) growing in sterile sand: soil (2:1) mixture in the greenhouse.

Nematode inoculum was prepared by extracting M. hapla eggs from galled tomato roots using sodium hypochlorite technique (Hussey and Baker, 1973). The egg suspension was aerated for 10-14 days at room temperature to facilitate hatching of eggs into J-2. Plants were inoculated with a 
nematode suspension containing $6000 \mathrm{~J}-2$ by dispensing the nematodes into a 3-cm-wide depression made around pyrethrum's root system. The depression was then covered with soil.

Plants without the fungus and the nematode served as controls. The treatments were arranged in a randomized complete design with six replications. The tests were terminated 2 months after nematode inoculation.

\section{Data collection}

\section{Plant performance}

Dry shoot and fresh root weights were obtained at the end of the experimental period. Shoot systems were dried at $80 \mathrm{C}$ for 48 hours before obtaining their weights.

\section{Root colonization by the fungus}

Thoroughly washed fine roots were cut into 1-cm-long segments and thoroughly mixed. Five $1 \mathrm{~g}$ fresh root samples per experimental unit were taken for assessment of fungal colonization. The roots were cleared and stained using Walker's Cold Staining technique, a modification of the technique of Phillip and Hayman (1970). The roots were observed under a dissecting microscope (Mag. x40) for the presence of aseptate intraradical hyphae, vesicles, arbuscules, spores, extraradical hyphae and auxillary cells. Root colonization was assessed using a Grid-Line Intersect Method (Giovanneti and Mosse, 1980). Colonized root length was expressed as a percentage of total root length.

\section{Nematode disease assessment}

To assess nematode damage on pyrethrum, the following parameters were obtained:

i) Galling index as a measure of disease severity. Roots were gently washed and rated for galling using a 0-4 galling scale where $0=$ no galls, $1=1-25 \%, 2=26-50 \%$, $3=51-75 \%$ and $4=76-100 \%$ of root system galled (Krusberg and Nelson, 1958)

ii) Number of females within the roots. A one-gram fresh root sample per experimental unit was cleared and stained using a modified $\mathrm{NaOCl}$-Acid fuchsin technique (Byrd et al., 1983). The number of females within the 1-cm-long root segments was determined under a dissecting microscope (Mag x40).

iii) Number of eggs within the root systems. Eggs were extracted using the technique of Hussey and Baker (1973). The egg suspension was adjusted to $50 \mathrm{ml}$ and the number of eggs in $1 \mathrm{ml}$ of the suspension was enumerated in a Hawksley's Slide Counter (Hawksley and Sons Ltd., West Sussex, England) under a microscope.

iv) Number of J-2 in soil. The J-2s were extracted from $100 \mathrm{~cm}^{3}$ of thoroughly mixed soil per experimental unit using the method of Jenkins (1964). The nematodes were enumerated in a Hawksley's Slide Counter.

\section{Data analysis}

Treatment effects were assessed by Analysis of Variance (ANOVA) using Statistical Analysis Systems (SAS) computer package. Treatment means were separated using Least Significant Difference (LSD).

\section{RESULTS}

There were highly significant differences $(\mathrm{P}<0.001)$ in dry shoot and fresh root weights among treatments (Table 1). Plants inoculated with Glomus LM61 and Scutellospora KS74 had the heaviest and second heaviest top dry biomasses, respectively while those inoculated with the nematodes alone had the lightest top dry biomass (Table 1). Glomus LM61 and Scutellospora KS74 significantly improved pyrethrum's top dry biomass by $33 \%$ and $31 \%$, respectively, (Table 1). Plants treated with Glomus ML34 and ML35 and Gigaspora LM83 had top dry biomasses that did not differ significantly from each other or from the control (Table 1). Plants treated with both the fungal isolates and the nematodes performed significantly better than those treated with the nematodes alone (Table 1). The fungal isolates improved top dry biomasses of nematode- treated pyrethrum by over $100 \%$ except for Glomus ML34 which improved top dry biomass of nematode-treated plants by $87 \%$ (Table 1 ).

Nematode significantly reduced pyrethrum's top dry biomass by $49 \%$ relative to the control (Table 1 ). The presence of the nematodes did not, however, significantly affect the performance of plants treated with the fungal isolates except in Glomus ML35-treated plants (Table 1). This was revealed by the non- significant differences between plants treated with both the fungal isolates and the nematodes and those treated with the respective fungal isolates alone (Table 1). 
Table 1: Mean dry shoot weights (DSW), fresh root weights (FRW) and percent root colonization (\% RC) of pyrethrum treated with AM fungal isolates and/or nematode

\begin{tabular}{llll}
\hline Treatment & DSW $(\mathrm{g})$ & FRW $(\mathrm{g})$ & \%RC \\
\hline Scutellospora KS74 + N & $10.17 \mathrm{cde}$ & $18.69 \mathrm{~cd}$ & $42.4 \mathrm{bcde}$ \\
Gigaspora LM83 + N & $8.7 \mathrm{bc}$ & $20.97 \mathrm{def}$ & $38 \mathrm{bc}$ \\
Glomus ML35+ N & $10.65 \mathrm{e}$ & $18.3 \mathrm{bcd}$ & $14.9 \mathrm{a}$ \\
Glomus ML34+ N & $7.67 \mathrm{~b}$ & $18.2 \mathrm{bcd}$ & $16 \mathrm{a}$ \\
Glomus LM61+ N & $10.32 \mathrm{de}$ & $16.57 \mathrm{bc}$ & $51.61 \mathrm{e}$ \\
Scutellospora KS74 & $10.55 \mathrm{e}$ & $22.97 \mathrm{ef}$ & $48.4 \mathrm{cde}$ \\
Gigaspora LM83 & $8.06 \mathrm{~b}$ & $19.38 \mathrm{cde}$ & $40.2 \mathrm{bcd}$ \\
Glomus ML35 & $7.53 \mathrm{~b}$ & $14.43 \mathrm{ab}$ & $33.9 \mathrm{~b}$ \\
Glomus ML34 & $8.9 \mathrm{bcd}$ & $23.75 \mathrm{f}$ & $34 \mathrm{~b}$ \\
Glomus LM61 & $10.72 \mathrm{e}$ & $16.58 \mathrm{bc}$ & $48.7 \mathrm{de}$ \\
Nematode $(\mathbf{N})$ & $4.1 \mathrm{a}$ & $10.43 \mathrm{a}$ & - \\
Control & $8.04 \mathrm{~b}$ & $15.85 \mathrm{bc}$ & - \\
\hline LSD & 1.57 & 4.25 & 10.7 \\
\hline
\end{tabular}

Data are means of six replicates.

II Means in the same column that are followed by the same letter(s) are not significantly different $(\mathrm{P}>0.05)$ using LSD.

Plants treated with Glomus ML34 and Scutellospora KS74 had the heaviest and second heaviest fresh roots, respectively, that differed significantly $(\mathrm{P}<0.001)$ from the control (Table 1). Colonization of pyrethrum by these fungal isolates increased root weights by $50 \%$ and $45 \%$, respectively, as compared to the control (Table 1). The other isolates did not, however, significantly improve root weights as was revealed by non-significant differences between the fungi-treated plants and the control (Table 1). Roots of fungus-nematode treated plants were significantly $(\mathrm{P}<0.001)$ heavier than those of nematode-treated plants (Table 1). Glomus LM61, Gigaspora LM83, Scutellospora KS74, Glomus ML34 and Glomus ML35 increased root weights of nematode-treated plants by 59\%, 101\%, 79\%, $75 \%$ and $75 \%$, respectively (Table 1 ). Nematode-treated plants had significantly lighter roots than all the other plants (Table 1). In presence of the fungal isolates Glomus LM61 and ML35 or Gigaspora LM83, however, nematodes did not have significant effects on root weights (Table 1). Plants treated with both the nematodes and fungal isolates Glomus ML34 or Scutellospora KS74 had, however, significantly lighter fresh roots (loss of $31 \%$ and $23 \%$, respectively) relative to those of plants treated with the respective fungus alone (Table 1 ).

Root colonization by AMF differed significantly $(\mathrm{P}<0.05)$ among treatments (Table 1). Roots of plants treated with Glomus LM61 or Scutellospora KS74 alone or plus the nematodes were among those that were heavily colonized while those of plants treated with either Glomus ML34 or
ML35 plus the nematodes were among those that were lightly colonized (Table 1 ).

There were highly significant differences $(\mathrm{P}<0.001)$ in gall indices (disease severity), number of eggs, females and J2s among treatments (Table 2).

Table 2: Mean gall indices (GI), eggs, females and J-2 in pyrethrum treated with AM fungal isolates and /or nematodes

\begin{tabular}{lllll}
\hline Treatment & GI $^{\dagger}$ & Eggs/ml & Females/g & J2/100ml \\
\hline Scutellospora KS74 + N & $2.5 \mathrm{~b}^{\mathrm{II}}$ & $1544 \mathrm{~b}$ & $198.2 \mathrm{~b}$ & $597.17 \mathrm{~b}$ \\
Gigaspora $\mathbf{L M 8 3}+\mathbf{N}$ & $2.33 \mathrm{~b}$ & $1471 \mathrm{~b}$ & $226.2 \mathrm{bc}$ & $472.17 \mathrm{ab}$ \\
Glomus ML35+ N & $3.17 \mathrm{c}$ & $1847.8 \mathrm{c}$ & $234.7 \mathrm{~cd}$ & $741.84 \mathrm{c}$ \\
Glomus ML34+ N & $3.17 \mathrm{c}$ & $1812.67 \mathrm{c}$ & $242.3 \mathrm{~cd}$ & $785.5 \mathrm{c}$ \\
Glomus LM61+ N & $0.5 \mathrm{a}$ & $292.7 \mathrm{a}$ & $33.3 \mathrm{a}$ & $385.5 \mathrm{a}$ \\
Nematode (N) & $3.68 \mathrm{c}$ & $2003 \mathrm{~d}$ & $260.2 \mathrm{~d}$ & $1270.34 \mathrm{~d}$ \\
Control & - & - & - & - \\
\hline LSD & 0.65 & 190.3 & 30.3 & 127.4 \\
\hline
\end{tabular}

Data are means of six replicates.

${ }^{\dagger}$ Gall indices based on a $0-4$ gall rating scale; where $0=$ no galls, $1=1-25 \% \quad 2=26-50 \%, 3=51-75 \%$ and $4=76-100 \%$ of root system galled.

II Means in the same column that are followed by the same letter(s) are not significantly different $(\mathrm{P}>0.05)$ using LSD

Plants treated with nematodes had significantly higher gall indices, number of eggs, females and J-2s than those treated with Glomus LM61, Scutellospora KS74 and Gigaspora LM83 (Table 2). Number of eggs and J-2s in plants treated with Glomus ML34 and ML35 also differed significantly from those of plants treated with the nematodes alone (Table 2). Glomus LM61 reduced galling, number of eggs and, females and $\mathrm{J}-2$ by $86 \%, 85 \%, 87 \%$ and $70 \%$, respectively (Table 2). Gigaspora LM83, on the other hand, reduced galling, number of eggs, females and $\mathrm{J}-2$ by $37 \%, 27 \%, 13 \%$ and $63 \%$, respectively, while Scutellospora KS74 reduced the disease parameters by $32 \%, 23 \%, 23 \%$ and $53 \%$, respectively (Table 2). Glomus ML35 reduced the number of eggs and $\mathrm{J}-2$ by $8 \%$ and $42 \%$, respectively, while Glomus ML34 reduced the number of eggs by $10 \%$ and J-2 by $38 \%$ (Table 2 ).

\section{DISCUSSION}

The ability of AM Glomus LM61 and Scutellospora KS74 to significantly improve pyrethrum top dry biomasses (Table 1) confirms previous reports on the ability of AMF to enhance plant growth. All the fungal isolates significantly improved top dry biomasses of nematodetreated plants (Table 1). As with other AMF, the fungi might have enhanced growth of untreated and nematodeinfected plants through enhanced nutrient uptake and 
synthesis of plant growth promoting hormones, in particular, auxins, cytokinins and gibberellins (Allen et al., 1980, 1982). Improved nutrient uptake results from increased absorptive surface of the root system by AMF external mycelia. As external mycelia ramificate through the soil beyond the nutrient depletion zone they absorb and translocate mineral elements mainly phosphorus, zinc, iron, copper, boron and molybdenum to the root system (Linderman, 1994). The fungi might have in addition, improved water uptake from the growth medium (Hardie, 1985). Improved water uptake in AMF-colonized plant results indirectly from improved plant nutritional status (Harley and Smith, 1983), increased cytokinin levels (Allen et al., 1982) and/or increased number of vascular bundles (Daft and Okusanya, 1973). The particular mechanisms involved are being investigated.

The differences in efficacy of AMF isolates to improve pyrethrum growth might be explained by differences in their effectiveness to infect and colonize pyrethrum and their ability to grow in the soil and enhance nutrient uptake. Species and strains of AM fungi have been reported to differ in their effectiveness to increase nutrient uptake and plant growth. The ability of AMF to increase nutrient uptake is related to their ability to form extensive and well distributed hyphae in soil and throughout the developing root system. The ability of AMF hyphae to absorb mineral nutrients from the soil solution and the distance from the soil via the hyphae into the root also influences fungal effectiveness. In addition, the host-fungus compatibility, the mycorrhizal dependency of pyrethrum, fungal inoculum density and potential play a significant role in influencing fungal effectiveness (Abbott and Robson, 1985). Fungal species that are effective in improving plant growth have been reported to infect and colonize the host plant rapidly (Sanders et al., 1977). Scutellospora spp. for example, has been reported to infect and colonize plants relatively slowly as compared to the Glomus spp. (Abbott and Robson, 1985).

Fungal isolates had no significant effects on root weights except Scutellospora KS74 and Glomus ML34 (Table 1). The improved root weights might have been due to greater secondary cell wall development caused by fungal colonization rather than an increase in root biomass. Plant colonization by some AM fungi leads to an increase in the proportion of lignified and suberized higher order roots (Rajapakse and Miller, 1992).

The significantly lower gall indices, fewer females, eggs and $\mathrm{J}-2$ in nematode-AMF treated plants, in most cases (Table 2), confirm previous reports on the ability of AMF to suppress phytonematodes (Ingham, 1988; Francl, 1993;
Linderman, 1994). Glomus LM61 was the most effective in reducing nematode disease severity (gall index) followed by Scutellospora KS74 (Table 2). Glomus ML34, and ML35 did not, however, significantly reduce nematode damage on pyrethrum except for egg production and soil infestation by J-2 (Table 2). Significantly reduced egg production, gall indices and populations of $M$. incognita was reported on tomato inoculated with Glomus intraradices Schenck and Smith (Suresh et al., 1985) and on cotton inoculated with G. fasciculatum (Saleh and Sikora, 1984; Smith et al., 1986). Similar results were obtained by Sivaprasad et al. (1990) on P. nigrum inoculated with Glomus etunicatum Becker and Gerd. and by Carling et al. (1989) on soybean inoculated with G. margarita Becker and Hall. Development of $M$. incognita on cotton and M. hapla on onion from J2 to adults was delayed after inoculation with $G$. intraradices (Smith et al., 1986) and G. fasciculatum (Mac Guidwin et al., 1985), respectively. Inoculating chickpea with Glomus manihotis suppressed reproduction of $M$. javanica (Diederichs, 1987).

The fungi might have increased plant resistance or tolerance to $M$. hapla infection through improved plant growth and vigour (Bagyaraj, 1984), increased production of phenolic compounds (Dehne and Schonbeck, 1979), phytoalexins (Morandi, 1987) and lignin (Schonbeck, 1979). Increase in lignin and phenols in mycorrhizal roots were implicated in the reduction of $M$. javanica reproduction in tomatoes (Suresh et al., 1985). An increase in amount of vascular bundle (Daft and Okusanya, 1973; Ratnayake et al., 1978)in AMF-colonized plants might have compensated for the nematode-damaged xylem tissues and alleviated nematode's detrimental effects on water and mineral uptake and translocation.

The fungi might have, in addition, altered chemotatic attraction of M. hapla to pyrethrum roots by altering the quantity and quality of root exudation (Francl, 1993). Besides affecting the attractiveness of roots to the nematode, change in root exudates might have altered the microbial population and composition in the mycorrhizosphere to the detriment of the nematodes. In addition, alteration of protein metabolism frequently reported in mycorrhizal plants might have led to increases in amino acids such as serine, phenylalanine and arginine which have nemastatic properties (Ingham, 1988). These biochemical and structural changes might have negatively influenced nematode penetration, survival and development. The speculated mechanisms of M. hapla suppression by the AM isolates will be verifiedin future studies. 
Although Glomus ML34 and ML35 improved growth of nematode-infected plants, the presence of $M$. hapla affected growth and development of the fungal isolates as indicated by the reduced percent root colonization and consequently their stimulatory effects on pyrethrum growth (Table 1). The presence of the nematode did not, however, significantly affect root colonization by the other fungal isolates (Table 1). Nematodes may increase, decrease or have no effect on root colonization by AM fungi (Francl, 1993). The effect depends on the specific fungal species involved. Decreased sporulation of G. etunicatum on soybean by M. incognita (Carling et al., 1989) and decreased vesicle formation and mycelial growth in citrus by Radopholus similis (Cobb) Thorne (O' Bannon and Nemec, 1979) have been reported. Kellam and Schenck (1980), on the other hand, reported that $M$. incognita had no significant effect on soybean root colonization by $G$. macrocarpum.

It appears that in Glomus ML34- or ML35-nematode interaction there was mutual inhibition between the fungi and the nematode possibly through competition for host photosynthates (Francl, 1993). Arbuscular mycorrhiza fungi depend on the host for their carbohydrate requirements (Harley and Smith, 1983) while nematodes utilize host's photosynthates for their growth and development (Bird, 1974). Whereas AMF increase photosynthesis through enhanced mineral translocation, water uptake and synthesis of phytohormones (Harley and Smith, 1983), root - knot nematodes decrease photosynthesis through the reverse mechanisms; reduced uptake and translocation of mineral salts and water (Bird, 1974) and inhibition of phytohormone production and translocation ((McClure, 1977).

In addition to decreasing photosynthesis, nematodes act as metabolic sinks (McClure, 1977). The increased metabolic activities of giant cells stimulate mobilization of photosynthates from shoots to roots where they are removed and utilized by the feeding nematodes. By diverting photosynthates, altering nutrient flow patterns in the plant tissue and retarding root growth, nematodes enhance competition with fungus thereby affecting fungal growth and development. This may account for the decreased percent root colonization by Glomus ML34 and ML35 and their decreased stimulatory effects on pyrethrum growth by the nematode (Table 1).

\section{ACKNOWLEDGEMENT}

Much thanks to Prof. J. B. Morton of INVAM for identifying the fungal isolates. We feel greatly indebted to Field Officers attached to Pyrethrum Board of Kenya for their invaluable assistance given during sampling. We thank the German government for financing the research project through the German Academic Exchange Service (DAAD) and the Institute of Plant Diseases, University of Bonn, Germany for providing Laboratory facilities.

\section{REFERENCES}

Abbot, L. K. and Robson, A. D. (1985). The role of vesicular arbuscular mycorrhiza fungi in agriculture and the selection of fungi for inoculation. Australian Journal of Agricultural Research 33: 389-408.

Allen M. F., Moore, T. S. and Christensen, M. (1980). Phytohormone changes in Bouteloua gracilis infected by vesicular - arbuscular mycorrhizae. 1 . Cytokinin increases in the host plant. Canadian Journal of Botany, 58:371 - 374.

Allen M. F., Moore, T. S. and Christensen, M. (1982). Phytohormone changes in Bouteloua gracilis infected by vesicular - arbuscular mycorrhizae. II. Altered levels of gibberellin - like substances and abscissic acid in the host plant. Canadian Journal of Botany, 60:468-471.

Bagyaraj, D. J. (1984). Biological interactions with VA mycorrhiza fungi. In: VAmycorrhiza. Powell C. L. and Bagyaraj, D. J. (eds.), pp.131-153. CRC press, Boca Raton, FL.

Bird, A. F. (1974). Plant response to root-knot nematode. Annual Review of Phytopathology 12:69-85.

Byrd, D. W., Kirpartrick, T. and Baker, K. R. (1983). An improved technique for clearing and staining plant tissue for detection of nematodes. Journal of Nematology 15:142-143.

Carling, D. E. Roncadori, R. W. and Hussey, R. S. (1989). Interactions of vesicular-arbuscular mycorrhiza fungi, root-knot nematode and phosphorus fertilization on soybean. Plant Disease, 73:730-733.

Daft, M. J. and Okusanya, B. O. (1973). Effect of Endogone mycorrhiza on plant growth. VI. Influence of infection on the anatomy and reproductive development of four hosts. New Phytologist 72:1333-1339.

Dehne, H. W. and Schonbeck, F. (1979). The influence of endotrophic mycorrhiza on plant diseases. II. Phenol metabolism and lignification. Phytopathology $Z$ 95:210-216.

Diederichs, C. (1987). Interaction between five endomycorrhizal fungi and theroot - knot nematode Meloidogyne javanica on chickpea under tropical conditions. Tropical Agriculture 64:353-355.

Francl, L. J. (1993). Interaction of nematodes with mycorrhizae and mycorrhizal fungi. In: Nematodeinteractions. Wajid Khan M. (ed.), Chaplan and Hall, London, UK. 
Gerdemann, J. W. and Nicolson, T. H. (1963). Spores of mycorrhiza Endogone species extracted from soil by wet sieving and decanting. Transactions of the British Mycological Society 46:235-244.

Giovanetti, M. and Mosse, B. (1980). An evaluation of techniques for measuring vesicular-arbuscular mycorrhizal infection in roots. New Phytologist 84:489-500.

Hardie, K. (1985). The effect of removal of extraradical hyphae in water uptake by vesicular arbuscular mycorrhiza plants. New Phytologist 101:677-684.

Harley, J. L. and Smith, S. E. (1983). Mycorrhizal symbiosis. Academic press, London. 634 pp.

Hussey, R. S. and Baker, K. R. (1973). A comparison of methods of collectinginocula of Meloidogyne species, including a new technique. Plant Disease Report 57:1025-1028.

Ikahu, J. M. K. and Ngugi, C. W. (1989). Yield assessment of newly developed pyrethrum varieties in different ecological zones in Kenya. Pyrethrum post 17:21-23.

Ingham, R. E. (1988). Interactions between nematodes and vesicular arbuscular mycorrhizae. Agriculture, Ecosystems and Environment 24:169-182.

Janos, D. P. (1987). Roles of mycorrhizae in nutrient cycling and retention in tropical soils and organic matter. INTECOL. Bulleting 14:41-44.

Jenkins, W. R. (1964). A rapid centrifuge flotation technique for separating nematodes from soil. Plant Disease Report 48:692.

Kellam, M. K and Schenck, N. C. (1980). Interaction between a vesiculararbuscular mycorrhiza fungus and rootknot nematodes on soybeans. Phytopathology 70:293-296.

Krusberg, L. R. and. Nelson, L. W. (1958). Pathogenesis of root-knot nematodes to Porto Rico variety of sweet potato. Phytopathology 48:30-39.

Linderman, R. G. (1994). Role of vesicular arbuscular mycorrhiza fungi inbiocontrol. In: Mycorrhizae and plant health. Pfleger, F. L. and Linderman, R. G. (eds), pp. 1-26. The American Phytopathological Society, St. Paul, MN.

Mac Guidwin, E. A. Bird, G. W. and Safir, G. R. (1985). Influence of Glomus fasciculatum on Meloidogyne hapla infecting Allium cepa. Journal of Nematology 17:389-395.

McClure, M. A. (1977). Meloidogyne incognita. A metabolic sink. Journal of Nematology 9:88-90.
Morandi, D. (1987). VA mycorrhizae, nematodes, phosphorus and phytoalexins on soybean. In: Mycorrhizae in the next decade, Practical application and Research Priorities. Sylvia, D. M, Hung, L. L and Graham, J. H. (eds), Proceedings of the 7th North American Conference on Mycorrhiza, Institute of Food and Agricultural Sciences, University of Florida, Gaineville.

Morton, J. B. (1988). Taxonomy of VA mycorrhizal fungi: classification, nomenclature and identification. Mycotaxon 32:267-324.

O'Bannon, J. H. and Nemec, S. (1979). The response of Citrus limon seedlings to Symbiont Glomus etunicatum, and a pathogen Radopholus similis. Journal of Nematology 11:270-275.

Parlevliet, J.E. and Brewer, J .G. (1971). The Botany, Agronomy and Breeding of pyrethrum. Report of Ministry of Agriculture, Molo, Kenya.

Phillips, J. M. and Hayman, D. S. 1970. Improved procedures for clearing rootsand Staining parasitic and vesicular arbuscular mycorrhiza fungi. Transactions of the British Mycological Society 55:158-160.

Rajapakse, S. and Miller, Jr. J. C. (1992). Methods of studying vesicular-arbuscular mycorrhizal rootcolonization and related root physical properties. In: Methods in Microbiology, Vol. 24. Norris, J. R. Read, D. J. and Varma, A. K. (eds.), pp. 301-316. Academic Press, London.

Ratnayake, M., Leonard, R. T. and Menge, J. E. (1978). Root exudation in relation to supply ofphosphorus and its possible relevance to mycorrhiza formation. New Phytologist 81:543-552.

Saleh, H. and Sikora, R. A. (1984). Relationship between Glomus fasciculatum root colonization of cotton and its effect on Meloidogyne incognita. Nematologica 30:230-237.

Sanders, F.E., Tinker, P.B., Black, R.L.B. and Palmerley, S. M. (1977). The development of endomycorrhizal root systems. 1. Spread of infection and growth-promoting effects with four species of vesicular-arbuscular endophyte. New Phytologist 78:257-268.

Schenck, N. C. and Perez, Y. (1987). A manual for identification of vesicular-arbuscular mycorrhizal fungi. INVAM. University of Florida. Gainesville, FL.

Schonbeck, F. (1979). Endomycorrhiza in relation to plant diseases. In: Soil-borne plant pathogens Schippers, B. and Gams, W. (eds), pp. 271-280. Academic Press, London. 
Sikora, R.A. (1979). Predisposition to Meloidogyne infection by endotrophic mycorrhiza fungus Glomus mosseae. In: Root-knot nematodes (Meloidogyne Species), Systematics, Biology and Control. Lamberti, F. and Taylor, C. E. (eds), pp. 300-4 04. Academic Press, New York.

Sivaprasad, P. Jacob, A., Nair, S.K. and George, B. (1990). Influence of VA mycorrhizal colonization on root-knot nematode infestation in Piper nigrum L. In: Trends in Mycorrhizal Research. Jalali, B.L. and Chand, H. (eds), pp.100-101. Proceedings of the National conference on Mycorrhiza, Haryana Agricultural University, Hissar.

Smith, G. S. Hussey, R. S. and Roncadori, R. W. (1986). Penetration and post infection development of Meloidogyne incognita on cotton as affected by Glomus intraradices and phosphorus. Journal of Nematology 18:429-435.

Suresh, C. K. Bagyaraj, D. J. and Reddy, D. D. R.(1985). Effect of Vesicular Arbuscular Mycorrhiza on survival, penetration and development of root-knot nematode in tomato. Plant and soil 87:305-308.

Triantaphyllou, A. C. (1985). Cytogenetics, cytotaxonomy and phylogeny of root-knot nematodes. In: $A n$ advanced treatise on Meloidogyne, Vol. 1 Biology and Control. Sasser, J. N. and Carter, C.C. (eds), pp. 113-126. North Carolina State University Graphics, Raleigh.

Walker, C. (1983). Taxonomic concepts in Endogonaceae. Spore wall characteristics in species descriptions. Mycotaxon 18:443-455.

Wanjala, B. W. (1992). Investigations into control of nematodes and fungal diseases in pyrethrum fields in Kenya. Pyrethrum Post 18:94-99.

Warui, C. M. Ikahu, J. M. K. and NgugI, C. W. (1991). Root rot infection,nematode infestation and splittability of pyrethrum clones multiplied through tissue culture technique. Pyrethrum Post 18:104-107. 